\title{
Physiological Effects of Squash vein yellowing virus Infection on Watermelon
}

Scott Adkins, T. Greg McCollum, and Joseph P. Albano, United States Department of Agriculture-Agricultural Research Service (USDA-ARS), U.S. Horticultural Research Laboratory, Fort Pierce, FL 34945; Chandrasekar S. Kousik, USDA-ARS, U.S. Vegetable Laboratory, Charleston, SC 29414; Carlye A. Baker, Florida Department of Agriculture and Consumer Services, Division of Plant Industry, Gainesville, FL 32945; Craig G. Webster, USDA-ARS, U.S. Horticultural Research Laboratory, Fort Pierce, FL 34945; Pamela D. Roberts, University of Florida, Department of Plant Pathology, Southwest Florida Research and Education Center, Immokalee, FL 34142; Susan E. Webb, University of Florida, Department of Entomology and Nematology, Gainesville, FL 32611; and William W. Turechek, USDA-ARS, U.S. Horticultural Research Laboratory, Fort Pierce, FL 34945

\begin{abstract}
Adkins, S., McCollum, T. G., Albano, J. P., Kousik, C. S., Baker, C. A., Webster, C. G., Roberts, P. D., Webb, S. E., and Turechek, W. W. 2013. Physiological effects of Squash vein yellowing virus infection on watermelon. Plant Dis. 97:1137-1148.

Squash vein yellowing virus (SqVYV) is the cause of viral watermelon vine decline. The virus is whitefly-transmitted, induces a systemic wilt of watermelon plants, and causes necrosis and discoloration of the fruit rind. In the field, SqVYV is often detected in watermelon in mixed infections with other viruses including the aphid-transmitted Papaya ringspot virus type $\mathrm{W}$ (PRSV-W). In this study, watermelon plants of different ages were inoculated with SqVYV or SqVYV+PRSV-W in the greenhouse or SqVYV in the field to characterize the physiological response to infection. Symptoms of vine decline appeared about 12 to 16 days after inoculation with SqVYV regardless of plant age at time of inoculation, plant growth habit (trellised or nontrellised), and loca-

tion (greenhouse or field). However, the presence of PRSV-W delayed the appearance of vine decline symptoms by 2 to 4 days, and vine decline did not develop on plants with no fruit. For all inoculation treatments, more severe symptoms were observed in younger watermelon plants. Physiological responses to SqVYV infection included reduction in plant and fruit weights, alterations in fruit rind and flesh color, reduction in fruit sucrose content, increase in fruit acid content, and changes in plant nutrient composition, particularly increases in $\mathrm{Ca}$, $\mathrm{Mg}, \mathrm{B}, \mathrm{Mn}$, and $\mathrm{Zn}$ and decreases in $\mathrm{K}$ and $\mathrm{N}$. These results demonstrate wide-ranging physiological effects of SqVYV infection and provide new insights into watermelon vine decline.
\end{abstract}

Plant viruses are obligate parasites that require a living host to support their replication. As such, many viruses induce no or mild symptoms upon infection (especially in hosts with which they have co-evolved), although these types of virus-host interactions are only recently being studied (12). Much research has focused on understanding virus-plant interactions that produce obvious disease symptoms including mosaics, ring spots, and chlorosis. However, these symptoms do not usually lead to death of the plant host. Citrus tristeza virus-induced quick decline of citrus grown on sour orange rootstocks (20) and Tobacco mosaic virus-induced collapse of Nicotiana benthamiana are notable exceptions, where a virus leads to rapid death of the plant host. Several species in the genus Ipomovirus also induce dramatic symptoms and/or death in some plant hosts including Cucumber vein yellowing virus-induced death of melons (17) and some cucumber cultivars (24), Cassava brown streak virus- and Ugandan cassava brown streak virusinduced necrosis of stems and tuberous roots of cassava $(28,37)$, and Squash vein yellowing virus- (SqVYV) induced death of watermelon (Citrullus lanatus var. lanatus; 2). The physiological effects underlying these host plant responses remain largely unknown.

SqVYV was first isolated from squash (Cucurbita pepo L.) with vein yellowing symptoms in Florida (2) and determined to be an

Corresponding author: Scott Adkins, E-mail: scott.adkins@ ars.usda.gov

Mention of a trademark, warranty, proprietary product, or vendor does not constitute a guarantee by the U.S. Department of Agriculture and does not imply its approval to the exclusion of other products or vendors that also may be suitable.

Accepted for publication 9 March 2013.

http://dx.doi.org/10.1094/PDIS-01-13-0075-RE

This article is in the public domain and not copyrightable. It may be freely reprinted with customary crediting of the source. The American Phytopathological Society, 2013. ipomovirus (16). However, SqVYV is best known for causing the devastating disease watermelon vine decline $(4,11)$, in which it induces necrosis of watermelon petioles and stems leading to the rapid wilt and death of plants at or near harvest $(2,6)$. The virus and disease have subsequently been identified in Indiana (10), Georgia (34), and South Carolina (C. S. Kousik and S. Adkins, unpublished). Semipersistent transmission of SqVYV by the whitefly Bemisia tabaci (Gennadius), biotype B was recently demonstrated (33).

The overall effect SqVYV has on its watermelon host and the mechanism of vine decline are poorly understood. Anecdotally, it is known that infection with SqVYV induces changes in fruit color and flavor (11), but the underlying alterations in plant physiology responsible for these changes have not been characterized. It is also not clear what changes in the nutrient composition of the plant occur upon infection with SqVYV and whether such changes contribute to the decline response. When SqVYV was first discovered, it was often found in mixed infections with the aphid-transmitted Papaya ringspot virus type $\mathrm{W}$ (PRSV-W), and currently with the more recently introduced whitefly-transmitted Cucurbit leaf crumple virus $(\mathrm{CuLCrV})$ and Cucurbit yellow stunting disorder virus (CYSDV). The effect of mixed infections on watermelon vine decline is also not fully understood. In the studies reported here, we explored the SqVYV-watermelon interaction to gain insight into the physiological changes that occur during vine decline.

\section{Materials and Methods}

Virus sources. The original squash isolate of SqVYV and a previously described Florida watermelon isolate of PRSV-W were maintained in squash (Cucurbita pepo) 'Prelude II' (Seminis Seeds, Oxnard, CA) and watermelon 'Crimson Sweet,' respectively, by mechanical transmission using $20 \mathrm{mM}$ sodium phosphate buffer ( $\mathrm{pH} 7.0$ ) containing $0.1 \%$ (wt/vol) sodium sulfite and $1 \%$ (wt/vol) Celite (2,3). Leaves from infected 'Prelude II' and/or 'Crimson Sweet' plants were homogenized in this buffer and used as inoculum for 'Crimson Sweet' plants in the greenhouse and field trials described below. 
Effect of plant age greenhouse trial. The effects of plant age at time of inoculation and co-infection with PRSV-W on watermelon vine decline were assessed in our initial greenhouse trial. 'Crimson Sweet' seeds were sown in soilless growing medium (Fafard 4P; Conrad Fafard, Inc., Agawam, MA), and 132 seedlings were transplanted into 11.4-liter pots in the same medium 18 days later. After transplanting, plants were immediately trellised onto a soft cotton string tied to the greenhouse bench below the pot and looping over a wire $\sim 3.6 \mathrm{~m}$ above the bench surface and returning to be tied to the bench on the other side of the pot (Fig. 1). The greenhouse was maintained under natural lighting with a daytime high of $30^{\circ} \mathrm{C}$. Insects were managed by a drench application of imidacloprid (Admire Pro; Bayer Crop Science, Research Triangle Park, NC). Routine insecticide and fungicide sprays were applied per standard production practices for management of insects and fungal diseases
(21). Plants were trimmed every 3 days to maintain a single stem. Female flowers were hand pollinated at first appearance (starting when plants were 41 days old) to produce a single fruit per plant. Fruits were supported by slings constructed from cheesecloth or mesh citrus bags suspended from the overhead wire.

Plants were grouped by inoculation treatment to minimize contamination. Treatments consisted of inoculation with buffer (mock), SqVYV, or SqVYV+PRSV-W of 11 plants each at four plant ages. Inoculum was prepared immediately before use (as described above) for inoculation of the first 7 to 10 fully expanded leaves on each plant. Inoculations were made when plants were 42 , 55,69 , or 83 days old. The same leaves were inoculated a second time 6 or 7 days after the first inoculation. Plants were observed daily for symptoms of vine decline, which appeared at 12 to 16 days after the first inoculation. Entire plants were collected for

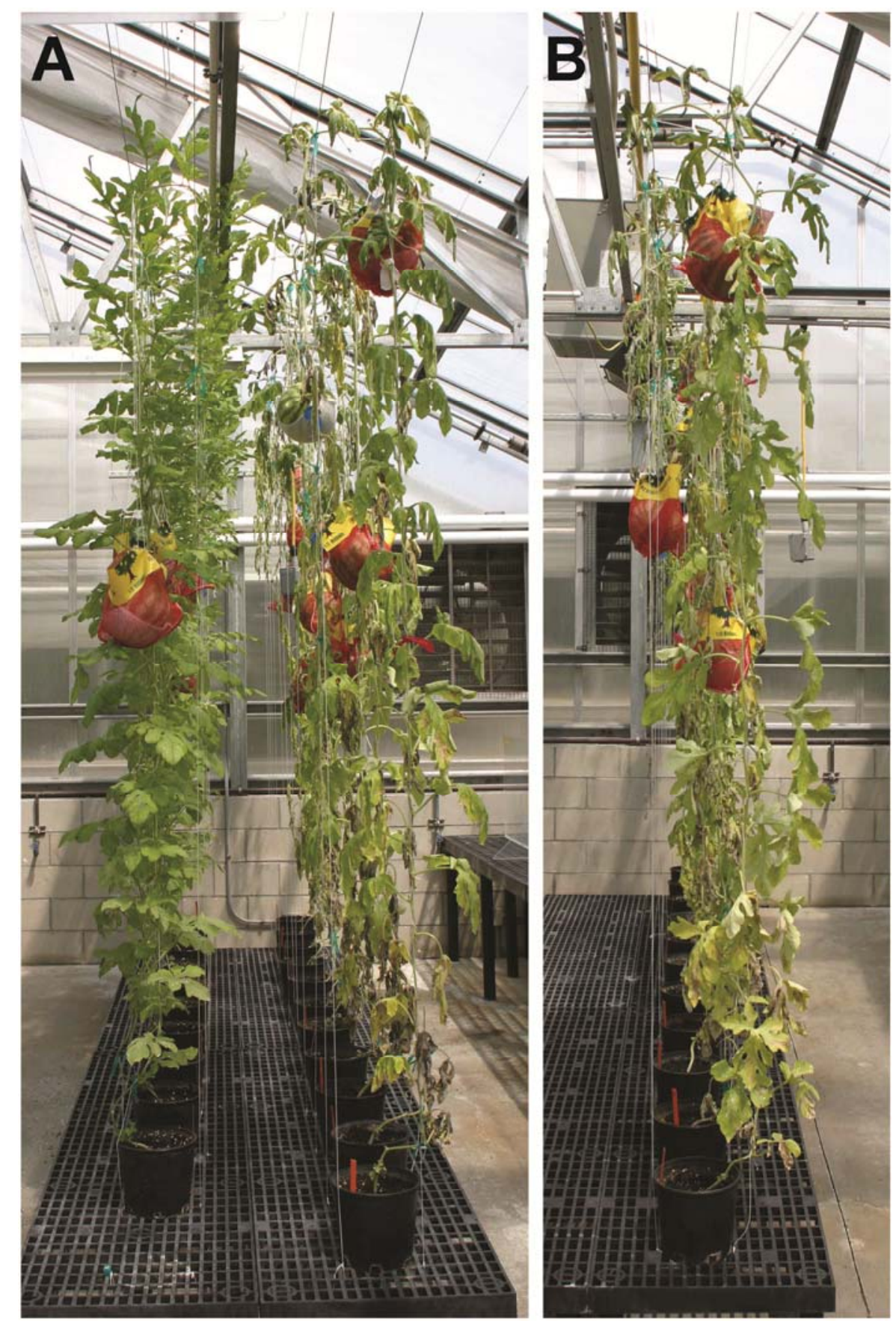

Fig. 1. 'Crimson Sweet' watermelon plants in plant age greenhouse trial. A, Mock- (left) and Squash vein yellowing virus- (SqVYV)- (right) inoculated plants. B, SqVYV+ Papaya ringspot virus type W-inoculated plants. Fruits are supported in mesh citrus fruit bags. All plants were inoculated at 83 days old and are shown at 96 days old (13 days postinoculation). 
subsequent analysis at 14 to 16 days after the first inoculation when plants were $57,71,84$, or 97 days old.

Effects of trellising and fruit greenhouse trial. The effects of trellised (vertical) or nontrellised (horizontal) plant growth, and fruit or no fruit on development of watermelon vine decline were assessed in a second greenhouse trial. 'Crimson Sweet' seeds were sown as above, and 32 seedlings were transplanted into 11.4-liter pots 14 days later. Fourteen plants were immediately trellised onto a soft cotton string as described above. Eighteen plants were grown nontrellised on greenhouse benches. All plants were maintained as a single stem, and insecticide and fungicide applications were made as described above. Flowers on seven trellised and 10 nontrellised plants were hand pollinated starting when plants were 36 days old to produce one fruit per plant. The remaining plants were not pollinated and did not produce fruit.

Plants were grouped by growth habit and inoculation treatment to minimize contamination. All plants were inoculated once with buffer (mock; six trellised and six nontrellised plants) or SqVYV (eight trellised and 12 nontrellised plants) as above when plants were 61 days old based on results from the plant age greenhouse trial. Plants were observed daily for appearance of symptoms of vine decline (12 to 16 days postinoculation [dpi]) and collected for subsequent analysis at 16 dpi when plants were 77 days old.

Virus detection. All greenhouse plants were tested for the presence of SqVYV (and PRSV-W in the plant age trial) by (i) tissue blot nucleic acid hybridization (SqVYV), (ii) reverse transcriptionpolymerase chain reaction (RT-PCR; SqVYV and PRSV-W), (iii) inclusion body morphology (SqVYV and PRSV-W), and/or (iv) commercially available enzyme-linked immunosorbent assay (ELISA, PRSV-W; Agdia, Elkhart, IN). Peduncles from each fruit were cut transversely with a new $0.30-\mathrm{mm}$ single edge surgical steel razor blade for each cut (American Safety Razor Co., Cedar Knolls, NJ) and used to make tissue prints on $10 \times 15 \mathrm{~cm}$ positively charged nylon membranes (Roche, Indianapolis, IN). Tissue blots were processed and hybridized with a digoxigenin-labeled SqVYV coat protein (CP) probe as previously described (29). Total RNA was subsequently extracted from peduncles using RNeasy Plant Mini Kit (Qiagen, Valencia, CA) for RT-PCR to detect SqVYV or PRSV-W using previously described conditions and CP primers (3). Epidermal strips were removed from the stem piece directly above where fruits were attached, and prepared, stained, and mounted on slides as previously described $(2,9)$. Slides were viewed on a light microscope for the presence or absence of viral inclusion bodies. ELISA followed the manufacturer's instructions.

Distribution of SqVYV within representative plants from both greenhouse trials was more extensively investigated by tissue blot. For the plant age trial, three plants, each inoculated at 55, 69, or 83 days old, were cut transverse to either the stem or petiole with new razor blades at the (i) crown, (ii) inoculated leaf, (iii) middle leaf (halfway between inoculated leaf and fruit), (iv) stem directly below fruit, (v) stem directly above fruit, (vi) upper leaf (halfway between fruit and stem tip), and (vii) stem tip to generate $\sim 2-\mathrm{cm}$ plant segments. Both ends of each segment were used to make a tissue print. Similarly, in the trellising and fruit effect trial, four trellised and eight nontrellised plants (half with fruits and half without) from both mock- and SqVYV-inoculated treatments were cut transverse to the stem with new razor blades at every second leaf from the crown through the stem tip to generate $\sim 2-\mathrm{cm}$ plant segments. Both ends of each segment were used to make a tissue print. Positive (SqVYV CP gene clone) and negative (PRSV-W CP gene clone) controls were included on all blots as 100-ng "spots" of plasmid DNA. All tissue blots were processed and hybridized as described previously (29).

Plant and fruit quality analysis in greenhouse trials. Following virus testing (described above) and nutrient analysis (described below for plant age trial), all remaining plant parts were weighed (fresh weight) and then oven dried at $80^{\circ} \mathrm{C}$ for 1 week to obtain dry weights. Fruits from the plant age trial were weighed at harvest and then cut longitudinally. Rind and flesh (placental) color were measured at three locations on each fruit using a tristimulus colorimeter
(Minolta CR 400, Ramsey, NJ) with an aperture of $8 \mathrm{~mm}$, D65 illuminant, and CIE L*a*b* color scale. A white-colored tile was used to calibrate the colorimeter. Data were expressed as $\mathrm{a} / \mathrm{b}$ ratios.

Flesh tissue was collected from each fruit in the plant age trial, weighed, and freeze dried. Samples were weighed again after freeze drying to calculate percent dry weight (fresh weight/dry weight $\times 100$ ). Soluble sugars were extracted from freeze dried placental tissue $(\sim 100 \mathrm{mg})$ by suspending the tissue in $10 \mathrm{ml}$ of deionized water and sonicating at $80^{\circ} \mathrm{C}$ for $10 \mathrm{~min}$. Following sonication, the extracts were centrifuged at $14,000 \times g$ for $15 \mathrm{~min}$. A $1.5-\mathrm{ml}$ aliquot of the clarified supernatant was filtered $(0.2 \mu \mathrm{m}$ nylon) and transferred to a new tube. Prior to analysis, the samples were diluted $100 \times$ with deionized water. Samples $(10 \mu \mathrm{l})$ were analyzed with a Shimadzu (Kyoto, Japan) LC-20AD liquid chromatograph equipped with an Alltech (Waukegen, IL) carbohydrate cation exchange column $\left(300 \times 6.5 \mathrm{~mm}\right.$; operated at $\left.90^{\circ} \mathrm{C}\right)$ and an evaporative light scattering detector (Shimadzu ELSDLTII). Sucrose, glucose, and fructose were quantified by the external standard method. Data were expressed as $\mathrm{mg} / \mathrm{g}$ fresh weight.

To determine titratable acidity, 0.5 -g aliquots of freeze dried placental tissue were suspended in $10 \mathrm{ml}$ of deionized water, vortexed for $1 \mathrm{~min}$, and then sonicated for $1 \mathrm{~h}$. An automatic titrator (Mettler DL50; Mettler-Toledo, Inc., Columbus, $\mathrm{OH}$ ) was used to measure titratable acidity. Samples were titrated with $0.1 \mathrm{~N} \mathrm{NaOH}$ to $\mathrm{pH}$ 8.2. Titratable acidity was calculated as percentage of malate as the predominant acid.

Nutrient assays. A 500-mg sample of oven-dried tissue from each entire plant in the plant age trial was ground using a Wiley mill (20 mesh; Thomas Scientific, Swedesboro, NJ) for nutrient analyses. Concentrations of $\mathrm{B}, \mathrm{Ca}, \mathrm{Cu}, \mathrm{Fe}, \mathrm{K}, \mathrm{Mg}, \mathrm{Mn}, \mathrm{Mo}, \mathrm{P}$, and Zn were determined by inductively coupled plasma-optical emission spectroscopy (ICP-OES; model Intrepid; ThermoScientific, Waltham, MA) according to U.S. EPA Method 6010B (32) following microwave-assisted acid digestion according to U.S. EPA method 3052 (31) modified as follows: plant tissue was digested in $10 \mathrm{ml} 15.8 \mathrm{~N}$ trace-metal grade $\mathrm{HNO}_{3}$ for $10 \mathrm{~min}$ at $170^{\circ} \mathrm{C}$ and 300 psi (internal digestion-vessel conditions). Digestates were brought to volume $(100 \mathrm{ml})$ with distilled-deionized water and then gravity filtered through Whatman 541 (Whatman Int. Ltd., Maidstone, England) prior to analysis by ICP-OES. Total $\mathrm{N}$ analysis was performed on a 5-mg sample of the dried, milled plant tissue by flashcombustion gas chromatography (model NC 2100; CE Elantech Inc., Lakewood, NJ). Nutrients were compared with those reported for watermelon in Florida (21) to determine deficient, adequate, and high levels.

Data analysis for greenhouse trials. To analyze the plant age trial data, the three inoculation treatments and the plant ages at the first inoculation were combined in a complete factorial with 11 blocks (i.e., the individual plants, generally 11 per treatment). Sucrose concentration and the $\mathrm{a} / \mathrm{b}$ ratios for fruit rind and flesh were $\log$ transformed based on residual plot analyses. All other variables were analyzed directly. The response variables were analyzed in a generalized linear mixed model (GLMM) using the SAS Procedure PROC GLIMMIX treating "inoculation treatment" (i.e., mock, SqVYV, and SqVYV+PRSV-W) and "age at inoculation" as crossed factors and block as a random effect, specifying an identity link function, a Gaussian (normal) error distribution, and selecting the kenwardroger option for calculating the denominator degrees of freedom. Treatment differences were obtained using the LSMEANS statement with the LINES option (the default being Fisher's LSD).

Preliminary analyses of the data from the trellising and fruit effect trial showed no differences between growth habit. So trellised and nontrellised data were pooled and similarly analyzed in a GLMM as above treating "fruit status" (fruit versus no fruit) and "inoculation treatment" (mock- versus SqVYV-inoculated) as crossed factors. Treatment differences were obtained using the LSMEANS statement with the LINES option.

Effect of plant age field trials. Four-week-old 'Crimson Sweet' watermelon seedlings were transplanted into Immokalee fine sand 
at the Southwest Florida Research and Education Center, University of Florida/IFAS in Immokalee, FL. Raised beds were prepared following fumigation with methyl bromide (50:50) and covered with black (fall) or white (spring) plastic mulch. Immediately following transplanting, a soil drench of imidacloprid (Admire Pro) was applied at the rate of $560 \mathrm{ml} \mathrm{ha}^{-1}$. Three sprays of spiromesifen (Oberon 2SC, Bayer CropScience) at the rate of $490 \mathrm{ml} \mathrm{ha}^{-1}$ were applied throughout the season to manage whiteflies. Standard production practices were followed including fungicide applications to manage foliar diseases (21).

Plots were arranged in a randomized complete block design with three blocks, apart from the exceptions in 2010 listed below. Each treatment replicate contained five plants. In 2007, the "plant age at inoculation" treatment consisted of plant ages of $28,44,58$, or 65 days corresponding to inoculation dates of 11 September, 27 September, 11 October, or 18 October. In 2008, the plant age at inoculation treatment consisted of plant ages of 28, 44, or 56 days, corresponding to inoculation dates of 22 September, 8 October, or 20 October, and a set of noninoculated controls. In 2010, the plant

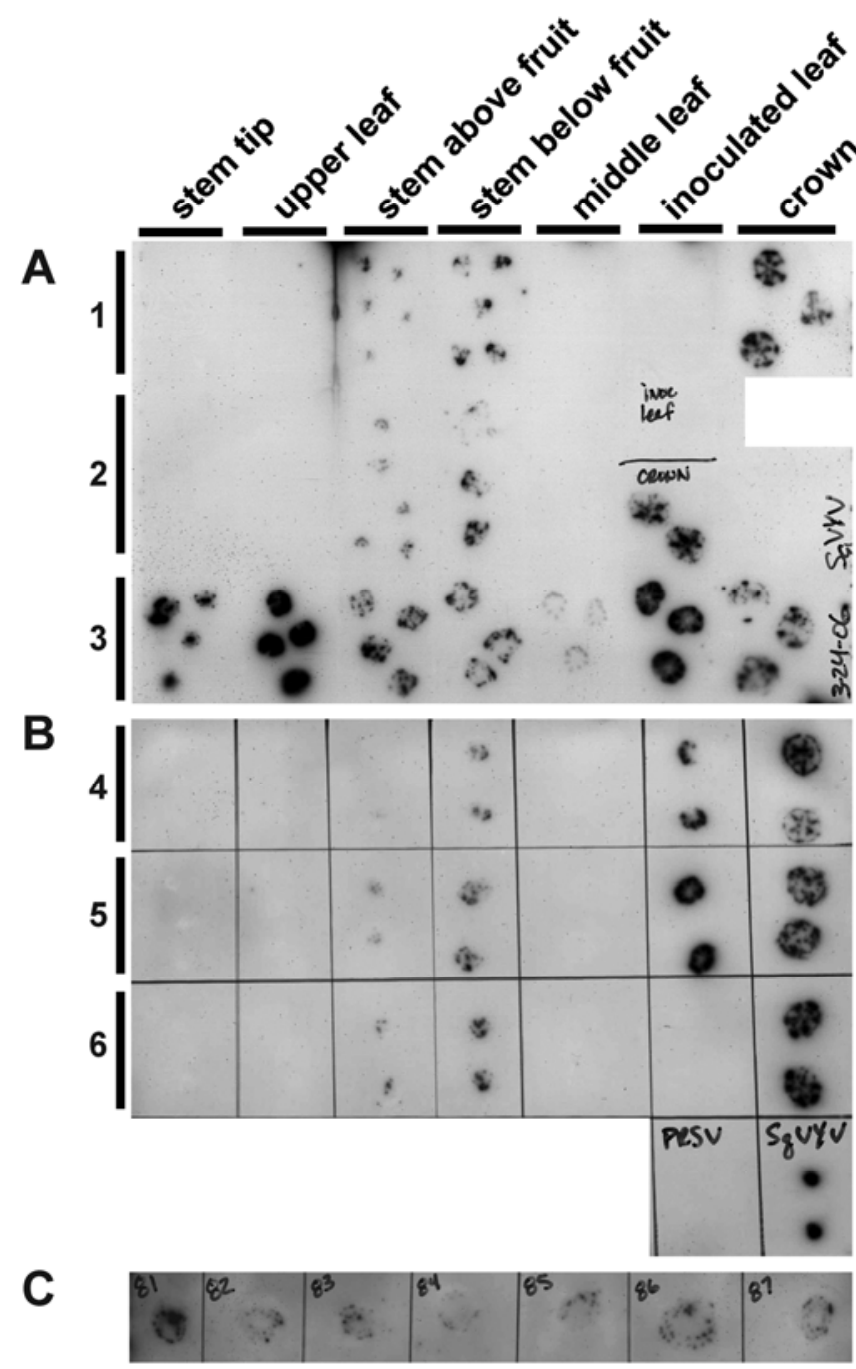

Fig. 2. Squash vein yellowing virus (SqVYV) distribution in representative 'Crimson Sweet' watermelon plants in plant age greenhouse trial as determined by tissueblot nucleic acid hybridization. A, Three plants $(1,2$, and 3$)$ inoculated with SqVYV at 55 days old. B, Three plants $(4,5$, and 6$)$ inoculated with SqVYV at 69 days old. Transverse cuts were made to stem with new razor blades at indicated plant region from the crown through the stem tip to generate $\sim 2 \mathrm{~cm}$ plant segments used to make a tissue print. Crown of plant 2 in $\mathrm{A}$ is below inoculated leaf tissue prints. $\mathrm{C}$, Peduncles of fruits from plants inoculated with SqVYV at 69 days old were cut flush with the fruit with new razor blades and used to make a tissue print. Control plasmid DNA "spots" of $100 \mathrm{ng}$ of SqVYV (positive) and PRSV-W (negative) coat protein gene clones were included on all blots and are shown in B. All tissue blots were processed and hybridized as described previously (29). age at inoculation treatment consisted of plant ages of 28, 38, 73, or 87 days, corresponding to inoculation dates of 22 March, 1 April, 6 May, or 20 May, and a set of noninoculated controls. The control plots and the plots inoculated on 6 and 20 May had only two replications. All plants were mechanically inoculated with homogenized SqVYV-infected 'Prelude II' leaf tissue as described above. Plants were rated for SqVYV symptoms using the 1 to 9 scale described previously (14). In 2007, plants were rated on 27 September, 18 October, 27 November, and 10 December. In 2008, plants were rated on 29 September, 8 October, 20 October, 19 November, and 8 December. In 2010, plants were rated on 1 April, 8 April, 15 April, 6 May, 13 May, 20 May, and 3 June.
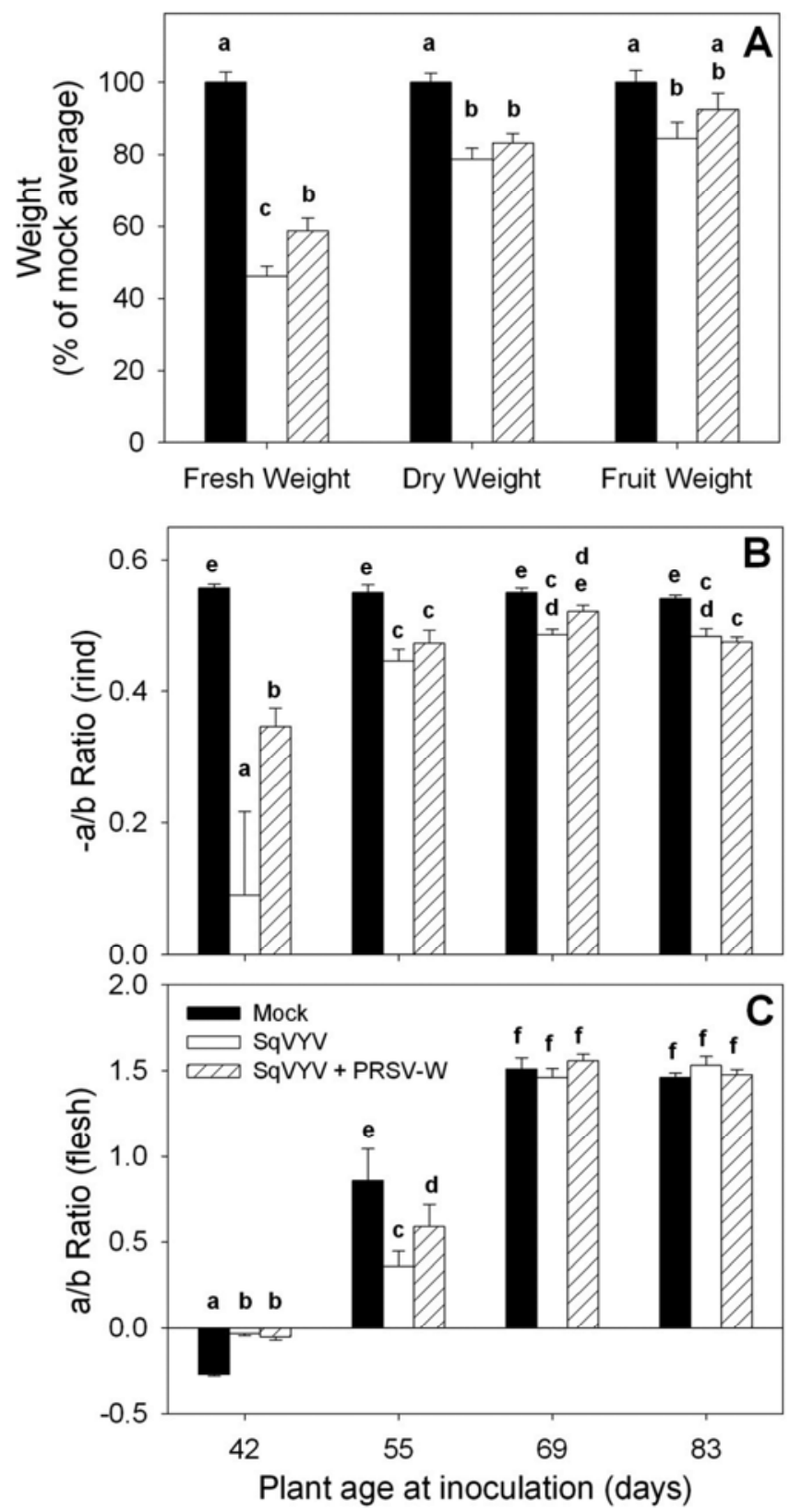

Fig. 3. Effect of virus inoculation treatment (mock-, Squash vein yellowing virus[SqVYV-], or SqVYV+Papaya ringspot virus type W- [PRSV-W-] inoculated) on watermelon physiology in plant age greenhouse trial. A, Plant fresh and dry weights, and fruit weights, by inoculation treatment. Samples from all plant ages were pooled by treatment because the interaction between plant age and inoculation treatment was not significant. Within each grouping (i.e., fresh weight, dry weight, and fruit weight), bars with same letter are statistically equivalent. B, a/b ratio of external fruit rind, and $\mathbf{C}$, flesh tissue by inoculation treatment from plants inoculated at four different ages $(42,55,69$, or 83 days old). Data are mean values ( \pm standard error) of the respective treatments. Bars with the same letter are statistically equivalent according to Fisher's LSD. 
For each set of inoculations, mean disease ratings were calculated from the five plants in each plot at each rating period, and the area under the disease progress curve (AUDPC) was calculated from these mean disease ratings. To determine if there was an effect of plant age on disease development, the AUDPCs and final disease severity were analyzed in a GLMM using the SAS procedure GLIMMIX, treating plant age at inoculation as a fixed effect and block as a random effect. Differences among treatments were determined with the LSMEANS statement using the LINES option.

\section{Results}

Plant age greenhouse trial. Symptoms typical of watermelon vine decline began to appear at 12 to 16 days after the first inoculation for all plants inoculated with SqVYV (Fig. 1). Plants inoculated at older ages and those co-inoculated with PRSV-W tended to require 2 to 4 additional days for symptom appearance. The initial symptom of SqVYV infection in most plants inoculated at all tested ages was the wilting of young leaves near the vine tip.

Table 1. Mixed model analysis summary of the effects of inoculation treatment ${ }^{\mathrm{a}}$ and plant age on 'Crimson Sweet' watermelon plant fresh and dry weights, fruit weight, rind and flesh colors, and sugar and acid contents in plant age greenhouse trial

\begin{tabular}{|c|c|c|c|c|c|c|c|c|c|c|c|c|}
\hline \multirow[b]{3}{*}{ Variable } & \multicolumn{4}{|c|}{ Plant age at inoculation $^{b}$} & \multicolumn{4}{|c|}{ Inoculation treatment ${ }^{b}$} & \multicolumn{4}{|c|}{ Age $\times$ inoculation ${ }^{b}$} \\
\hline & \multicolumn{2}{|c|}{$\mathbf{d f} \mathbf{f}^{\mathrm{c}}$} & \multirow[b]{2}{*}{$\boldsymbol{F}$} & \multirow[b]{2}{*}{$\boldsymbol{P}$} & \multicolumn{2}{|c|}{$d f^{c}$} & \multirow[b]{2}{*}{$\boldsymbol{F}$} & \multirow[b]{2}{*}{$\boldsymbol{P}$} & \multicolumn{2}{|c|}{$\mathbf{d f}^{\mathrm{c}}$} & \multirow[b]{2}{*}{$\boldsymbol{F}$} & \multirow[b]{2}{*}{$\boldsymbol{P}$} \\
\hline & Num & Den & & & Num & Den & & & Num & Den & & \\
\hline Plant fresh weight & 3 & 119 & 4.75 & 0.004 & 2 & 119 & 89.2 & $<0.001$ & 6 & 119 & 1.55 & 0.167 \\
\hline Plant dry weight & 3 & 119 & 36.2 & $<0.001$ & 2 & 119 & 18.2 & $<0.001$ & 6 & 119 & 1.34 & 0.245 \\
\hline Fruit weight & 3 & 95 & 671 & $<0.001$ & 2 & 94 & 3.34 & 0.040 & 6 & 93 & 1.58 & 0.161 \\
\hline $\log (\mathrm{a} / \mathrm{b}$ ratio rind $)$ & 3 & 93 & 34.1 & $<0.001$ & 2 & 91 & 84.35 & $<0.001$ & 6 & 91 & 14.2 & $<0.001$ \\
\hline $\log (\mathrm{a} / \mathrm{b}$ ratio flesh $)$ & 3 & 91 & 225 & $<0.001$ & 2 & 90 & 0.44 & 0.646 & 6 & 90 & 4.41 & 0.001 \\
\hline $\log$ (sucrose) & 2 & 16 & 169.7 & $<0.001$ & 2 & 16 & 7.40 & 0.005 & 4 & 16 & 0.36 & 0.833 \\
\hline Acid & 2 & 16 & 93.14 & $<0.001$ & 2 & 16 & 9.46 & 0.002 & 4 & 16 & 4.64 & 0.011 \\
\hline
\end{tabular}

a Mock-inoculated, Squash vein yellowing virus-inoculated, or Squash vein yellowing virus+Papaya ringspot virus type $\mathrm{W}$-inoculated.

${ }^{\mathrm{b}}$ The three inoculation treatments and the plant ages were combined in a complete factorial. The individual plants, generally 11 per treatment, were treated as blocks. The response variables were analyzed individually in a generalized linear mixed model using the SAS Procedure PROC GLIMMIX treating 'plant age at inoculation' and 'inoculation treatment' as crossed factors and block as a random effect.

${ }^{c}$ Denominator degrees of freedom were calculated using the 'kenwardroger' method in SAS (13) and were rounded to a whole number for presentation.

Table 2. Nutrient concentrations in inoculated ' 'Crimson Sweet' watermelon tissue in plant age greenhouse trial

\begin{tabular}{|c|c|c|c|c|c|c|c|c|c|}
\hline \multirow[b]{2}{*}{ Nutrient $^{c}$} & \multirow[b]{2}{*}{ Treatment } & \multicolumn{2}{|c|}{42 days $^{b}$} & \multicolumn{2}{|c|}{55 days } & \multicolumn{2}{|c|}{69 days } & \multicolumn{2}{|c|}{83 days } \\
\hline & & Mean & $\mathbf{S E}^{\mathbf{d}}$ & Mean & SE & Mean & SE & Mean & SE \\
\hline \multicolumn{10}{|c|}{ Macronutrient (\%) } \\
\hline \multirow[t]{3}{*}{$\mathrm{Ca}^{\dagger}$} & Mock & 3.57 & 0.33 & 4.04 & 0.24 & 6.33 & 0.21 & 6.90 & 0.12 \\
\hline & SqVYV & 3.92 & 0.34 & 5.33 & 0.30 & 7.53 & 0.28 & 8.60 & 0.15 \\
\hline & SqVYV+PRSV-W & 3.79 & 0.17 & 6.17 & 0.40 & 6.91 & 0.26 & 8.10 & 0.23 \\
\hline \multirow{3}{*}{$\mathrm{K}^{\dagger}$} & Mock & 3.68 & 0.12 & 2.55 & 0.09 & 2.08 & 0.09 & 1.94 & 0.08 \\
\hline & SqVYV & 3.73 & 0.25 & 2.31 & 0.14 & 1.16 & 0.08 & 0.70 & 0.06 \\
\hline & SqVYV+PRSV-W & 3.30 & 0.26 & 2.21 & 0.16 & 1.99 & 0.12 & 1.08 & 0.08 \\
\hline \multirow[t]{3}{*}{$\mathrm{Mg}^{\dagger}$} & Mock & 1.02 & 0.08 & 0.96 & 0.04 & 1.13 & 0.03 & 1.13 & 0.04 \\
\hline & SqVYV & 1.06 & 0.06 & 1.34 & 0.07 & 1.44 & 0.04 & 1.31 & 0.04 \\
\hline & SqVYV+PRSV-W & 1.02 & 0.03 & 1.37 & 0.05 & 1.11 & 0.02 & 1.24 & 0.03 \\
\hline \multirow[t]{3}{*}{$\mathrm{N}^{\dagger}$} & Mock & 3.88 & 0.11 & 3.32 & 0.10 & 3.06 & 0.12 & 3.01 & 0.08 \\
\hline & SqVYV & 3.83 & 0.17 & 2.30 & 0.09 & 0.54 & 0.19 & 1.91 & 0.09 \\
\hline & SqVYV+PRSV-W & 3.48 & 0.13 & 2.59 & 0.13 & 1.17 & 0.17 & 2.10 & 0.09 \\
\hline \multirow[t]{3}{*}{$\mathrm{P}$} & Mock & 0.58 & 0.02 & 0.36 & 0.01 & 0.40 & 0.01 & 0.35 & 0.01 \\
\hline & SqVYV & 0.62 & 0.02 & 0.38 & 0.01 & 0.35 & 0.01 & 0.31 & 0.01 \\
\hline & SqVYV+PRSV-W & 0.65 & 0.02 & 0.42 & 0.02 & 0.33 & 0.01 & 0.29 & 0.01 \\
\hline \multicolumn{10}{|c|}{ Micronutrient $\left(\mu \mathrm{g} \mathrm{g}^{-1}\right)$} \\
\hline \multirow[t]{3}{*}{$\mathrm{B}^{\dagger}$} & Mock & 56.21 & 3.10 & 55.37 & 2.87 & 74.20 & 3.14 & 78.59 & 2.54 \\
\hline & SqVYV & 56.43 & 3.84 & 69.91 & 3.62 & 93.84 & 3.67 & 95.87 & 4.98 \\
\hline & SqVYV+PRSV-W & 60.20 & 2.79 & 80.62 & 3.59 & 87.84 & 5.11 & 92.37 & 4.67 \\
\hline \multirow[t]{3}{*}{$\mathrm{Cu}$} & Mock & 11.53 & 1.37 & 9.75 & 0.46 & 13.45 & 0.50 & 12.88 & 0.40 \\
\hline & SqVYV & 11.33 & 0.27 & 8.98 & 0.29 & 14.31 & 0.44 & 13.65 & 0.39 \\
\hline & SqVYV+PRSV-W & 11.67 & 0.37 & 10.94 & 0.57 & 13.51 & 0.25 & 13.54 & 0.46 \\
\hline \multirow[t]{3}{*}{$\mathrm{Fe}$} & Mock & 67.91 & 3.58 & 62.45 & 2.08 & 73.10 & 2.41 & 67.71 & 3.47 \\
\hline & SqVYV & 73.26 & 2.25 & 61.75 & 2.18 & 62.14 & 2.18 & 68.34 & 3.83 \\
\hline & SqVYV+PRSV-W & 69.03 & 2.63 & 64.65 & 2.93 & 65.87 & 1.32 & 61.98 & 3.13 \\
\hline \multirow[t]{3}{*}{$\mathrm{Mn}^{\dagger}$} & Mock & 47.77 & 3.45 & 71.66 & 5.25 & 106.99 & 2.82 & 123.67 & 6.43 \\
\hline & SqVYV & 63.65 & 6.80 & 71.18 & 3.87 & 110.29 & 4.99 & 127.16 & 7.44 \\
\hline & SqVYV+PRSV-W & 54.25 & 2.61 & 74.82 & 5.85 & 119.38 & 4.12 & 155.87 & 6.51 \\
\hline \multirow[t]{3}{*}{ Mo } & Mock & 1.05 & 0.15 & 0.70 & 0.11 & 1.89 & 0.25 & 2.09 & 0.26 \\
\hline & SqVYV & 0.77 & 0.19 & 0.61 & 0.18 & 1.79 & 0.29 & 1.99 & 0.28 \\
\hline & SqVYV+PRSV-W & 0.81 & 0.13 & 0.61 & 0.13 & 2.31 & 0.31 & 2.14 & 0.23 \\
\hline \multirow[t]{3}{*}{$\mathrm{Zn}^{\dagger}$} & Mock & 51.13 & 3.54 & 51.98 & 4.42 & 52.39 & 3.63 & 55.87 & 3.69 \\
\hline & SqVYV & 72.77 & 3.86 & 39.72 & 2.23 & 52.69 & 5.56 & 64.70 & 5.04 \\
\hline & SqVYV+PRSV-W & 83.03 & 4.57 & 51.19 & 4.09 & 63.59 & 4.23 & 72.34 & 6.20 \\
\hline
\end{tabular}

\footnotetext{
${ }^{a}$ Mock-inoculated, Squash vein yellowing virus- (SqVYV-) inoculated, or SqVYV+Papaya ringspot virus type W- (PRSV-W-) inoculated.

${ }^{\mathrm{b}}$ Plant age at first inoculation.

${ }^{c}$ Nutrients followed by ' $\dagger$ ' had a significant inoculation treatment effect $(P \leq 0.05)$.

d Standard error for the mean.
} 
Plants inoculated at all four ages were collected 14 to 16 days after the first inoculation and before death of SqVYV-infected plants occurred so that intact samples could be obtained. All virus-inoculated plants became infected. Virus infection was confirmed in all virus-inoculated plants by tissue blot nucleic acid hybridization, RT-PCR, inclusion body morphology, and/or
ELISA. Virus infection was also confirmed in the two mockinoculated plants that developed symptoms (about 14 days following inoculation) during the course of the trial (presumably due to whitefly transmission of SqVYV from virus-inoculated plants within the trial). Tissue blot nucleic acid hybridization demonstrated localization of SqVYV nucleic acid in watermelon
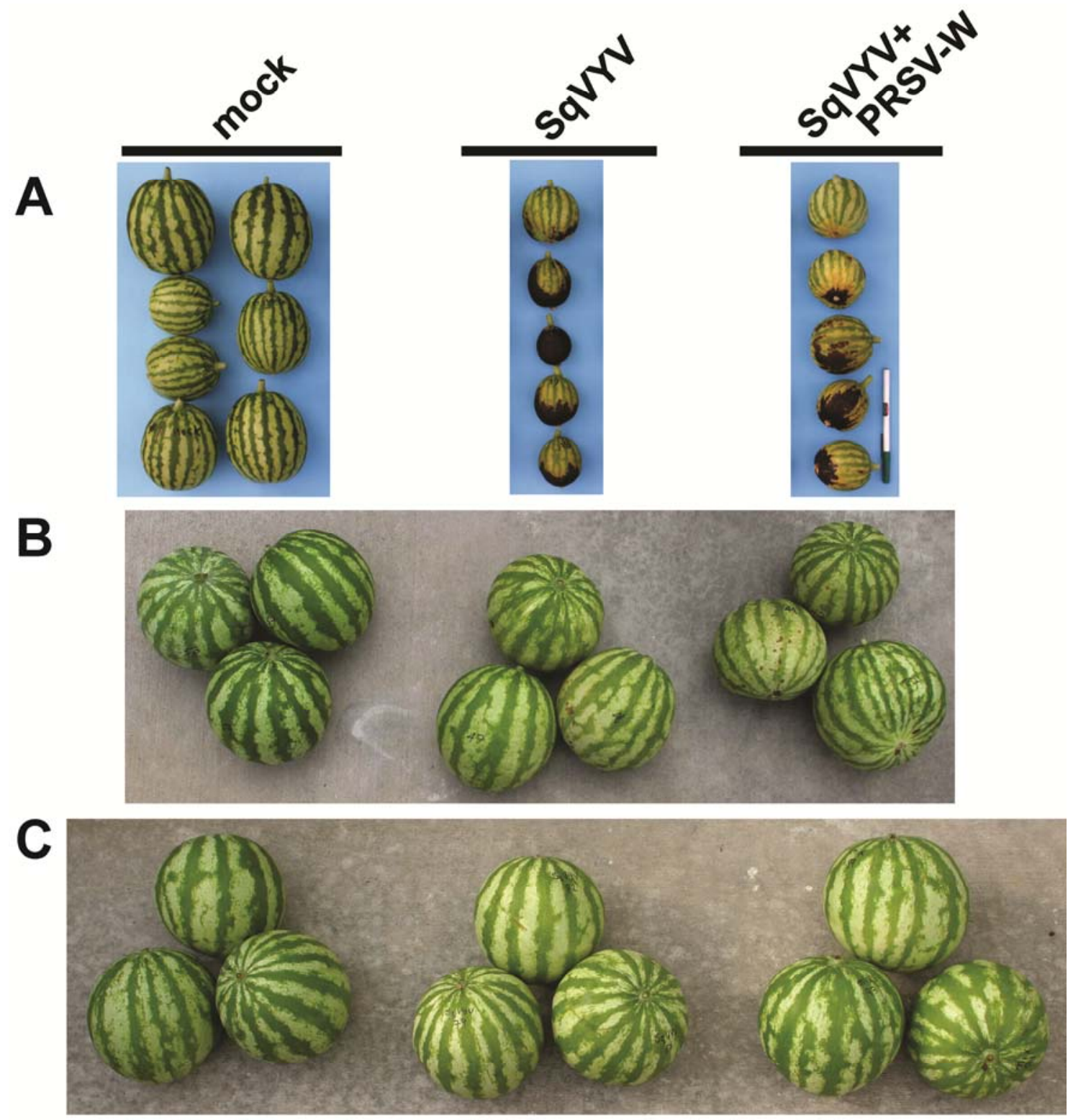

D

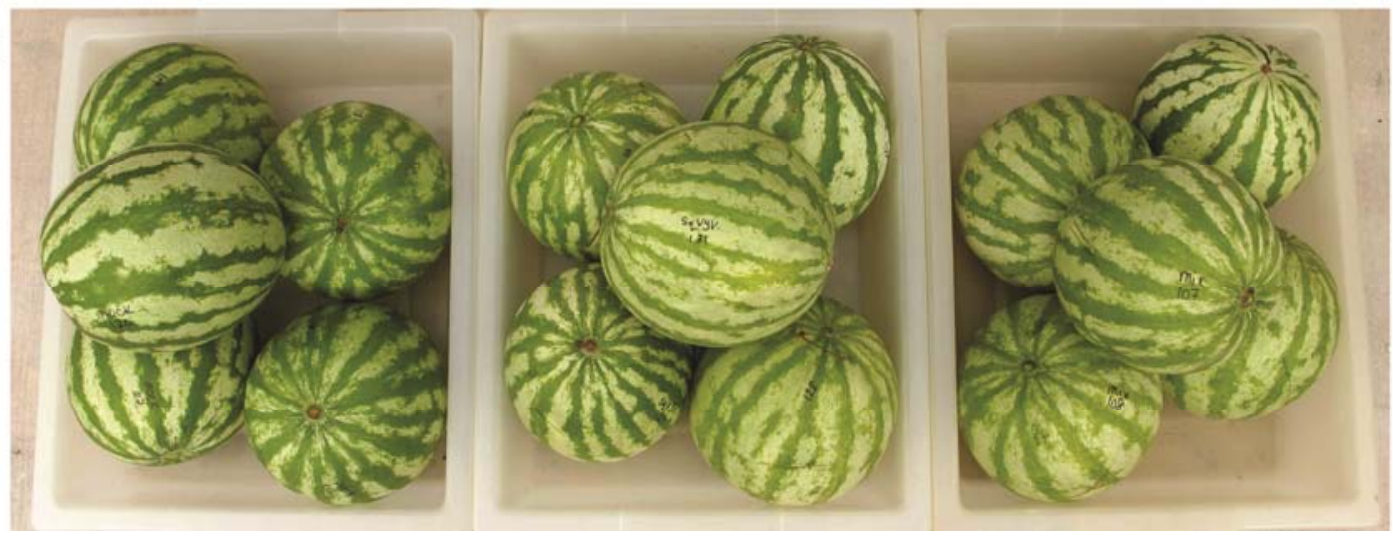

Fig. 4. Whole 'Crimson Sweet' watermelon fruits from plant age greenhouse trial showing external rind color. A, All fruits from plants inoculated at 42 days old, and representative fruits from plants inoculated at B, 55, C, 69, or D, 83 days old. Fruits are grouped by inoculation treatment: Mock- (mock), Squash vein yellowing virus- (SqVYV-), or SqVYV+Papaya ringspot virus type W- (PRSV-W-) inoculated. 
vascular system (Fig. 2; note black spots where vascular tissue occurs).

In SqVYV- and SqVYV+PRSV-W-infected plants (with fruit) first inoculated at 55 days old, SqVYV was detected throughout the plant in one of the three plants extensively sampled, and only from the crown up to the point of fruit attachment in two of the three plants extensively sampled (Fig. 2A). SqVYV was also found throughout a symptomatic mock-inoculated plant inoculated at 55 days old (data not shown). In SqVYV- and SqVYV+PRSV-Winfected plants inoculated at 69 or 83 days old, SqVYV was only found from the crown up to the point of fruit attachment (Fig. 2B) in all six plants extensively sampled. Similarly, SqVYV was also found only from the crown up to the point of fruit attachment in a symptomatic mock-inoculated plant inoculated at 69 days old (data not shown). SqVYV was consistently detected in peduncles of SqVYV-infected plants inoculated at all ages with fruit (Fig. 2C) as previously determined (29).

Infection with either SqVYV or SqVYV+PRSV-W had significant deleterious effects on plant fresh and dry weights (Fig. 3A; Table 1). Fresh weights of SqVYV+PRSV-W-infected plants were greater than those of SqVYV-infected plants. This mirrored the progression of symptom development, where SqVYV+PRSV-Winfected plants started wilting 2 to 4 days later than SqVYV-infected plants (Fig. 1), and thus weighed more at the time of collection. Dry weights of the plants did not differ significantly, indicating that fresh weight differences between SqVYV- and SqVYV+PRSV-W-infected plants were due to either extra water retained in the SqVYV+PRSV-W-infected plants or dehydration of the SqVYV-infected plants due to reduced water uptake, rather than differences in plant growth. Infection with either SqVYV or SqVYV+PRSV-W reduced mean fruit weights, but this difference was only significant from the mock-inoculated treatment for plants infected with SqVYV alone (Fig. 3A). Reductions in plant and fruit weights diminished with increasing plant age at time of inoculation (data not shown).

Rind color of fruits from mock-inoculated plants was more green and less yellow than for fruits from either virus-inoculated treatment (Fig. 4; Table 1). This was particularly noticeable in plants inoculated at 42 days old, where all fruits from virus-infected plants exhibited obvious chlorosis/necrosis at the blossom end (Fig. 4A). Rumpling of the rind and splitting of fruits from virus-infected plants was observed in plants inoculated at older ages. There was a significant interaction between $\mathrm{a} / \mathrm{b}$ ratios (shown as negative $\mathrm{a} / \mathrm{b}$ ratios in Fig. 3B) and plant age at time of inoculation, with rind color differences decreasing with increasing plant age at time of inoculation (Fig. 3B).

Similarly, flesh color of fruits from mock-inoculated plants differed in color from flesh of fruits from either virus inoculation treatment (Fig. 5; Table 1). This difference was particularly noticeable in plants inoculated at 42 or 55 days old, where all fruits from virus infected plants exhibited internal necrosis (Fig. 5A and B) and cell separation at the blossom end (Fig. 5A; top fruit in SqVYV and SqVYV+PRSV-W columns). In plants inoculated at 69 or 83 days old, flesh of fruits from virus infected plants appeared over-ripe and water-soaked, with necrosis confined to the rind (Fig. 5C and D). A statistically significant interaction between $\mathrm{a} / \mathrm{b}$ ratios and plant age supported visual ratings (Fig. 3C). In plants inoculated at 55 days old, flesh of fruits from SqVYV+PRSV-Winfected plants more closely resembled flesh of fruits from mockinoculated plants. In contrast, fruits from plants inoculated at 69 or 83 days old had no significant difference in flesh color.

Sucrose levels were significantly lower in fruits from SqVYVand SqVYV+PRSV-W-infected plants compared to mock-inoculated plants for all plant ages at inoculation (Fig. 6A; Table 1). In plants older at inoculation, sucrose levels in fruits from SqVYV+ PRSV-W-infected plants were similar to those in fruits from mock-inoculated plants. No significant effects of virus infection on glucose or fructose levels were observed (data not shown). Fruits of mock-inoculated plants tended to have lower titratable acidity than fruits from virus-inoculated plants (Fig. 6B), but acid content was only significantly lower in plants inoculated at 55 days old.

Nutrient analysis of plant age greenhouse trial plants. Analysis of mock-inoculated plants and comparison to established stand-
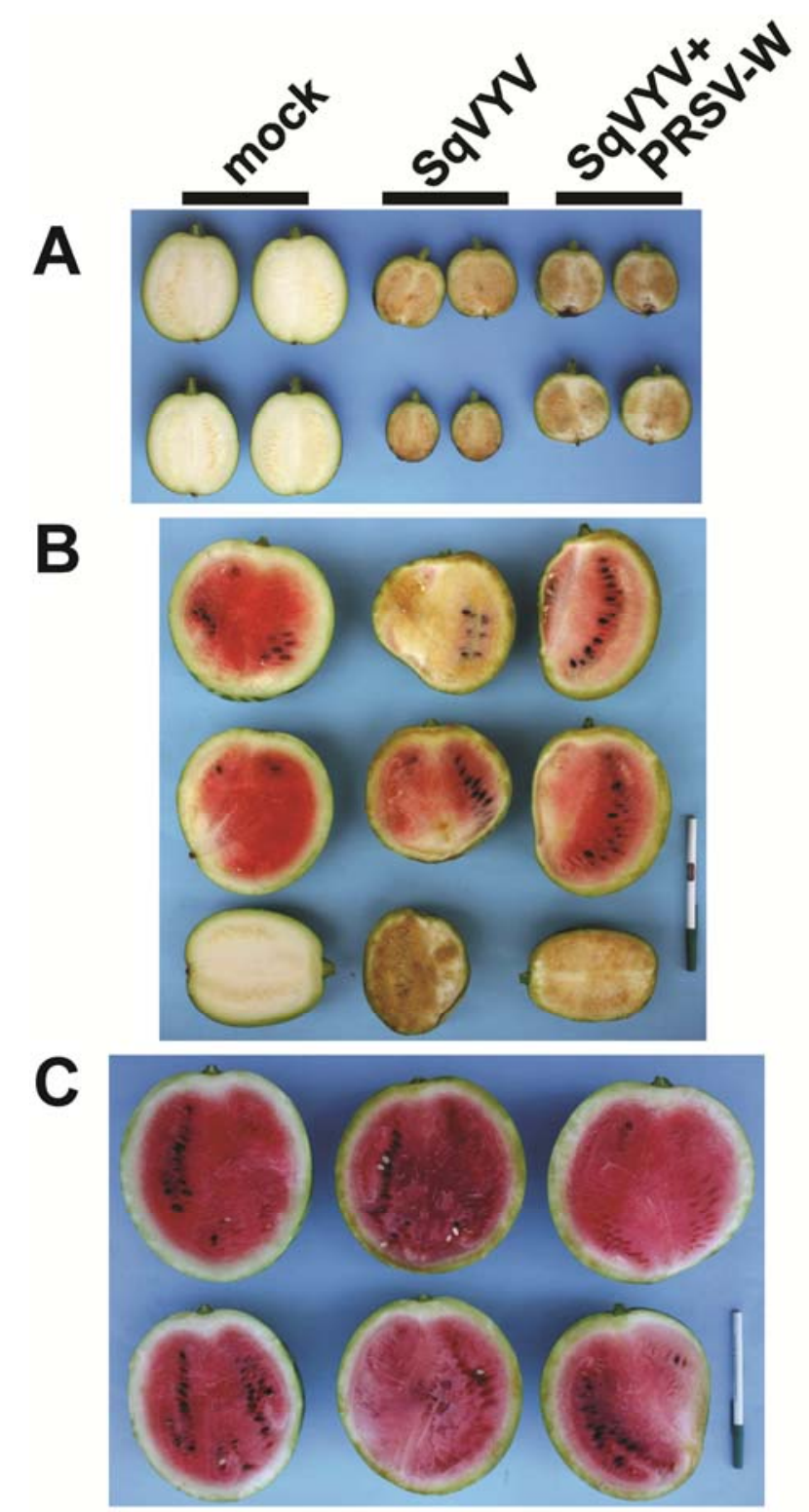

D

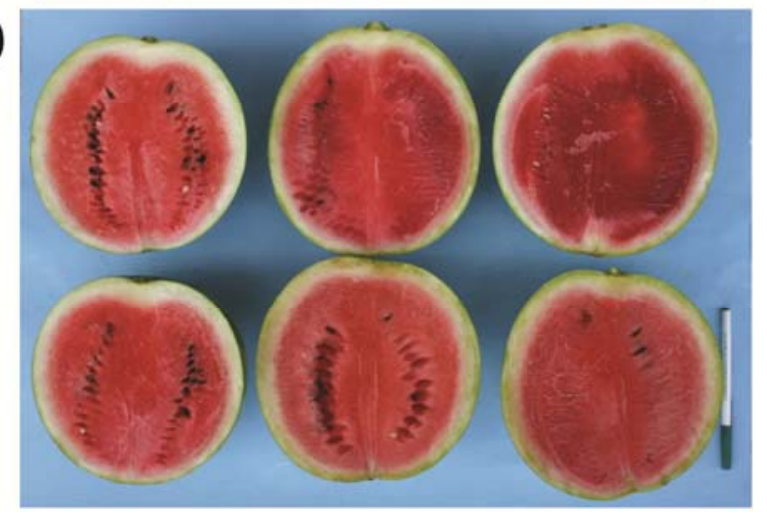

Fig. 5. Cut 'Crimson Sweet' watermelon fruits from plant age greenhouse trial showing internal rind and flesh color. A, Both halves of two representative fruits from plants inoculated at 42 days old, and representative halves of fruits from plants inoculated at B, 55, C, 69, or D, 83 days old. Fruit halves are grouped by inoculation treatment: Mock- (mock), Squash vein yellowing virus- (SqVYV-), or SqVYV+Papaya ringspot virus type W- (PRSV-W-) inoculated. 
ards for Florida watermelon (21) indicated adequate to high levels of all nutrients were present in plant tissue for all plant ages at time of inoculation, with the exception of $\mathrm{K}$, which decreased to deficiency in older plants. Significant treatment effects were identified
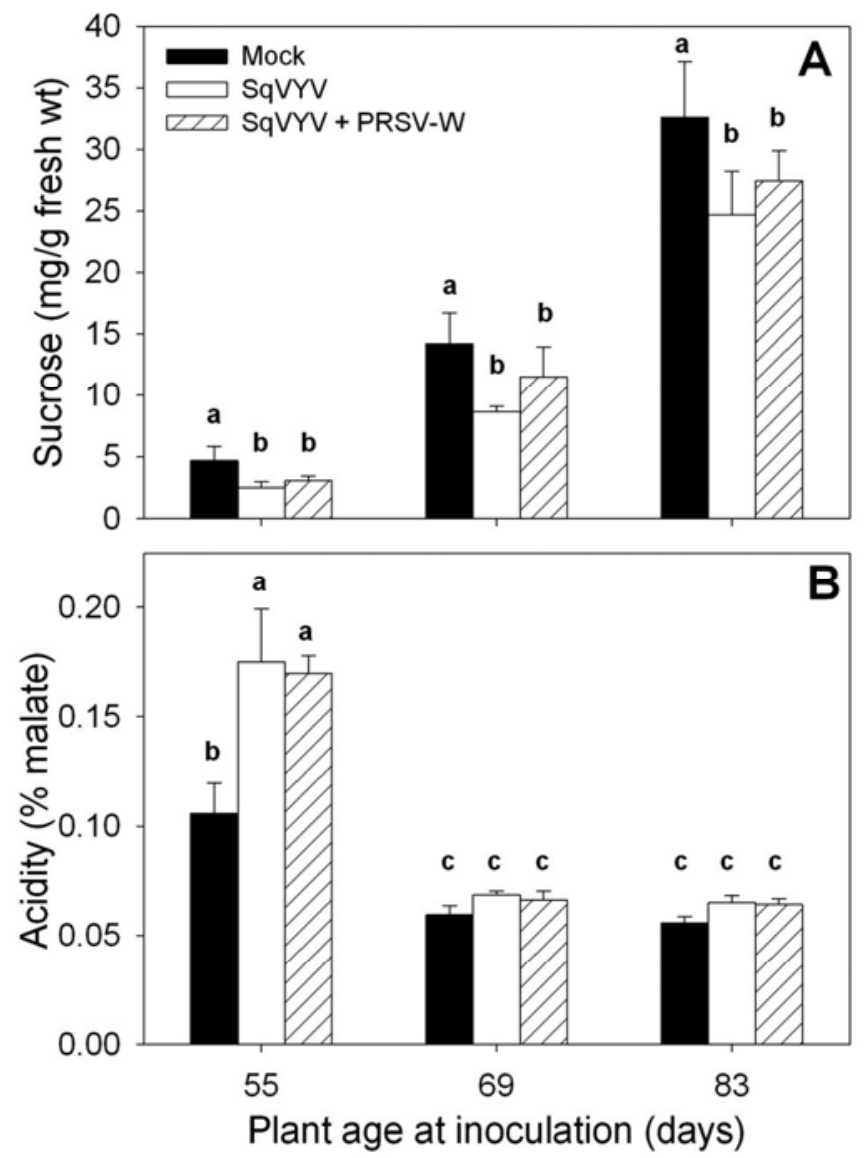

Fig. 6. Fruit quality data from 'Crimson Sweet' watermelon plants in plant age greenhouse trial. A, Sucrose (mg/g fresh wt) and B, Acidity (\% malate) by inoculation treatment (mock-, Squash vein yellowing virus- [SqVYV-], or SqVYV+ Papaya ringspot virus type $\mathrm{W}-[\mathrm{PRSV}-\mathrm{W}$-] inoculated). Data are the mean values ( \pm standard error) for the respective inoculation treatments. In A, there was no interaction between the variables 'inoculation treatment' and 'plant age.' Therefore, bars with same letter in A are statistically equivalent within each grouping according to Fisher's LSD, unlike in B, where differences are across groupings. for macronutrients $\mathrm{N}, \mathrm{K}, \mathrm{Ca}$, and $\mathrm{Mg}$ (Table 2). The percentages of $\mathrm{N}$ and $\mathrm{K}$ were high $(>3.5 \%$ for mock- and SqVYV-inoculated plants) or at the upper end of adequate $(<3.5 \%$ for SqVYV+PRSVW-inoculated plants) for plants inoculated at 42 days old but declined to deficient or near-deficient levels in both virus inoculation treatments for plants inoculated at 55 days or older. For mockinoculated plants, the percent $\mathrm{N}$ remained adequate throughout the trial, whereas the percent $\mathrm{K}$ decreased to deficient levels $(<2.7 \%)$, although the percent $\mathrm{K}$ remained about twice the level in plants inoculated with SqVYV at 69 or 83 days old, or SqVYV+PRSV-W at 83 days old. The percentages of $\mathrm{Ca}$ and $\mathrm{Mg}$ were high $(>2.0 \%$ or $>0.5 \%$, respectively) for all treatments at all plant ages (Table 2). However, the percentage of Ca in SqVYV- and SqVYV+PRSV-Winoculated plants was greater than in mock-inoculated plants at all ages, and the percentage of $\mathrm{Mg}$ in SqVYV-inoculated plants was greater than in mock-inoculated plants for plants inoculated at 55 , 69 , or 83 days old. The percentage of Mg in SqVYV+PRSV-Winoculated plants was greater than in mock-inoculated plants for plants inoculated at 55 or 83 days old (Table 2). The percentage of $\mathrm{P}$ was adequate to high for plants inoculated at all ages and not significantly affected by treatment.

Significant treatment effects were observed for micronutrients B, $\mathrm{Mn}$, and $\mathrm{Zn}$. The level of B was high ( $>40 \mathrm{ppm}$ ) throughout the trial and increased with plant age at time of inoculation (Table 2). The level of B in SqVYV+PRSV-W-inoculated plants was greater than in mock-inoculated plants at all plant ages at time of inoculation, and in SqVYV-inoculated plants was greater than in mock-inoculated plants at 55, 69, or 83 days old. Similarly, the level of Mn increased from adequate (20 to $100 \mathrm{ppm})$ to high ( $>100 \mathrm{ppm}$ ) over the course of the trial. The level of $\mathrm{Mn}$ in both SqVYV and SqVYV+PRSV-W treatments was greater than in mock-inoculated plants for most plant ages at time of inoculation. The level of $\mathrm{Zn}$ was high (>40 ppm) throughout the trial with the exception of in SqVYV-inoculated plants at 55 days old, which was at the upper end of adequate (20 to $40 \mathrm{ppm})$. Both SqVYV and SqVYV+PRSV-W treatments had more $\mathrm{Zn}$ than mock-inoculated plants when inoculated at 42 or 83 days old, and SqVYV+PRSV-W-inoculated plants also had the most Zn when inoculated at 69 days old. Levels of micronutrients $\mathrm{Cu}, \mathrm{Fe}$, and Mo were adequate to high at all plant ages at time of inoculation and not significantly affected by treatment (Table 2).

Trellising and fruit effect greenhouse trial. Infection was confirmed in all virus-inoculated plants by tissue blot nucleic acid hybridization, RT-PCR, and/or inclusion body morphology. In plants with fruit, symptoms typical of watermelon vine decline began to appear at 12 to $16 \mathrm{dpi}$ for all plants inoculated with SqVYV. There was no difference in the time required for symptom

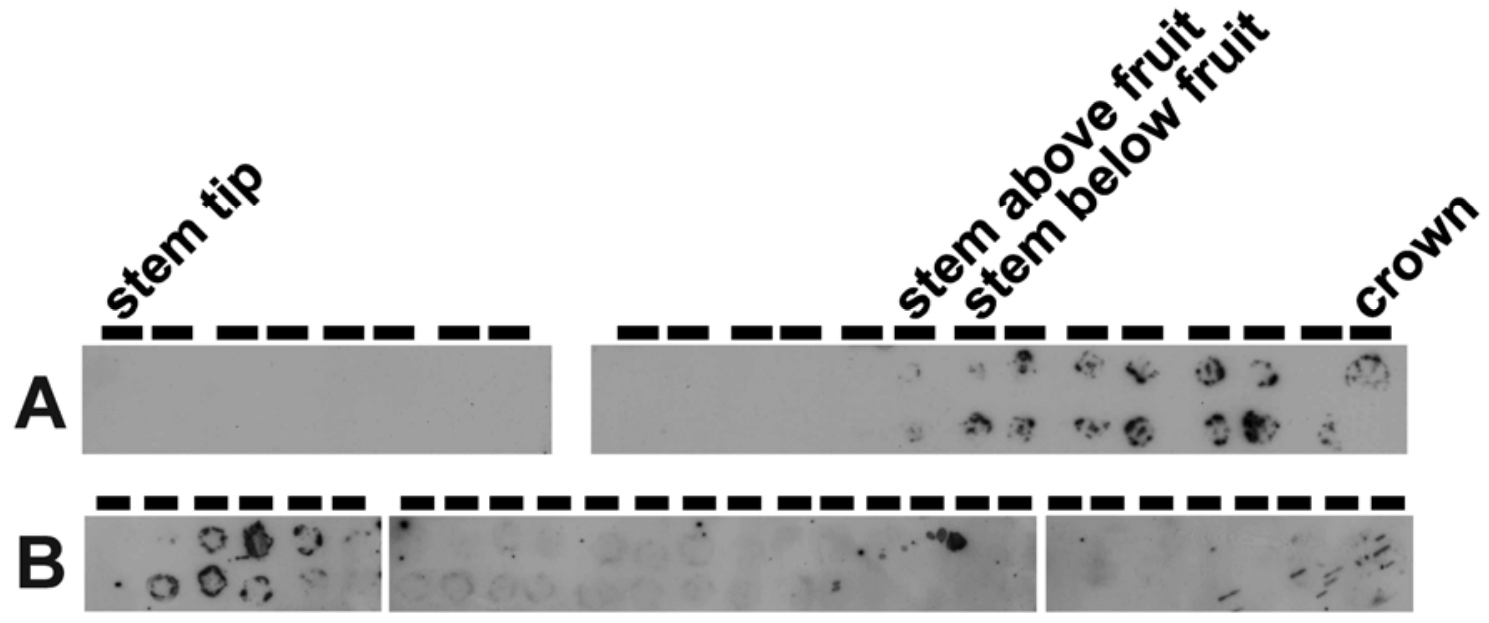

Fig. 7. Effect of fruit presence on Squash vein yellowing virus distribution in 'Crimson Sweet' watermelon plants in the trellising and fruit effect greenhouse trial. Representative tissue blots from trellised plants $\mathbf{A}$, with fruit or $\mathbf{B}$, without fruit, and inoculated at 61 days old. Transverse cuts were made to stem with new razor blades at every second leaf from the crown through the stem tip to generate $\sim 2 \mathrm{~cm}$ plant segments. Both ends of each segment were used to make a tissue print. All tissue blots were processed and hybridized as described previously (29). Stem sections flanking fruit attachment site are indicated in A. Plant without fruit (B) grew longer so there are additional samples in its tissue blot. 
appearance on trellised or nontrellised plants. Tissue blot nucleic acid hybridization again demonstrated localization of SqVYV nucleic acid in the watermelon vascular system, and in plants with fruit it was only found from the crown up to the point of fruit attachment in all plants extensively sampled (Fig. 7A). Interestingly, in plants without fruit, SqVYV nucleic acid was generally found only in the newest growth up to and including the stem tip (Fig. 7B). SqVYV-inoculated plants without fruit did not decline.

Infection with SqVYV significantly reduced plant fresh weights regardless of the presence of fruit (Fig. 8). Plants without fruit grew considerably larger and thus weighed more. In contrast, plant dry weights for SqVYV- and mock-inoculated plants with fruit did not differ significantly. Dry weights of SqVYV-inoculated plants without fruit remained significantly lower than mock-inoculated plants.

Plant age field trials. Inoculated plants developed typical SqVYV symptoms in all years. Noninoculated control plants also developed SqVYV symptoms, first observed 58 and 45 days after the first inoculation in the fall 2008 and spring 2010 trials, respectively. Presumably, inoculation of control plants was due to viruliferous whiteflies in the field. Based on visual examination of the disease progress curves, the rates of disease progress were very similar among age treatments in each trial, indicating limited effect of plant age (Fig. 9). However, the onset of watermelon vine decline was delayed for younger plants with less fruit load compared to older plants with greater fruit load. There was a significant effect of plant age on the AUDPC in 2008 and 2010, but not 2007 (Table 3). In 2008 and 2010, the largest AUDPC was associated with plants inoculated when 44 and 38 days old, respectively, corresponding to the second inoculation. In 2008, the AUDPC for plants inoculated at 44 days old was significantly different than the AUDPCs for all other plant ages according to Fisher's LSD (Fig. 9B). In 2010, the AUDPC for plants inoculated at 38 days old was significantly larger than the AUDPCs of plants 73 and 87 days old (third and fourth inoculations, respectively) but not 28 days old (first inoculation) (Fig. 9C). Despite the differences in the AUDPCs, final disease severity only differed in the fall 2007 trial with 44-day-old plants having significantly lower final disease severity than plants inoculated at 28 and 65 days old, but not at 58 days old (data not shown).

\section{Discussion}

The effects of SqVYV on the physiology and growth of watermelon were found to be significantly affected by the age at which

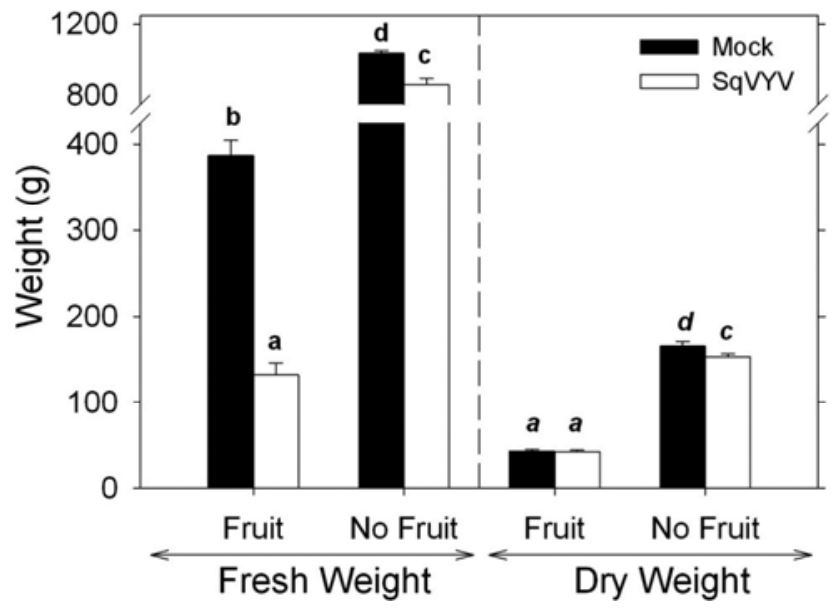

Fig. 8. Effect of fruit presence and Squash vein yellowing virus inoculation on whole plant fresh and dry weights of 'Crimson Sweet' watermelon plants in the trellising and fruit effect greenhouse trial. Fresh and dry weights $(\mathrm{g})$ of plants by inoculation treatment: (i) mock- or Squash vein yellowing virus- (SqVYV-) inoculated and (ii) fruit or no fruit. Trellised and nontrellised samples were pooled as the effect of trellising on vine decline development was not significant. Bars represent means \pm standard error. Bars with the same letter are statistically equivalent according to Fisher's LSD. Fresh weight comparisons are shown in standard text; dry weight comparisons are shown in italicized text. plants were inoculated. Despite these differences, watermelon plants of all ages inoculated with SqVYV developed decline symptoms at 12 to $16 \mathrm{dpi}$ whether grown trellised or nontrellised. The presence of PRSV-W delayed appearance of SqVYV-induced symptoms of vine decline by 2 to 4 days, but ultimately, all plants inoculated with SqVYV developed decline with the exception of plants without fruit. Moreover, the results of the two greenhouse trials further established that SqVYV is moving from the inocula-
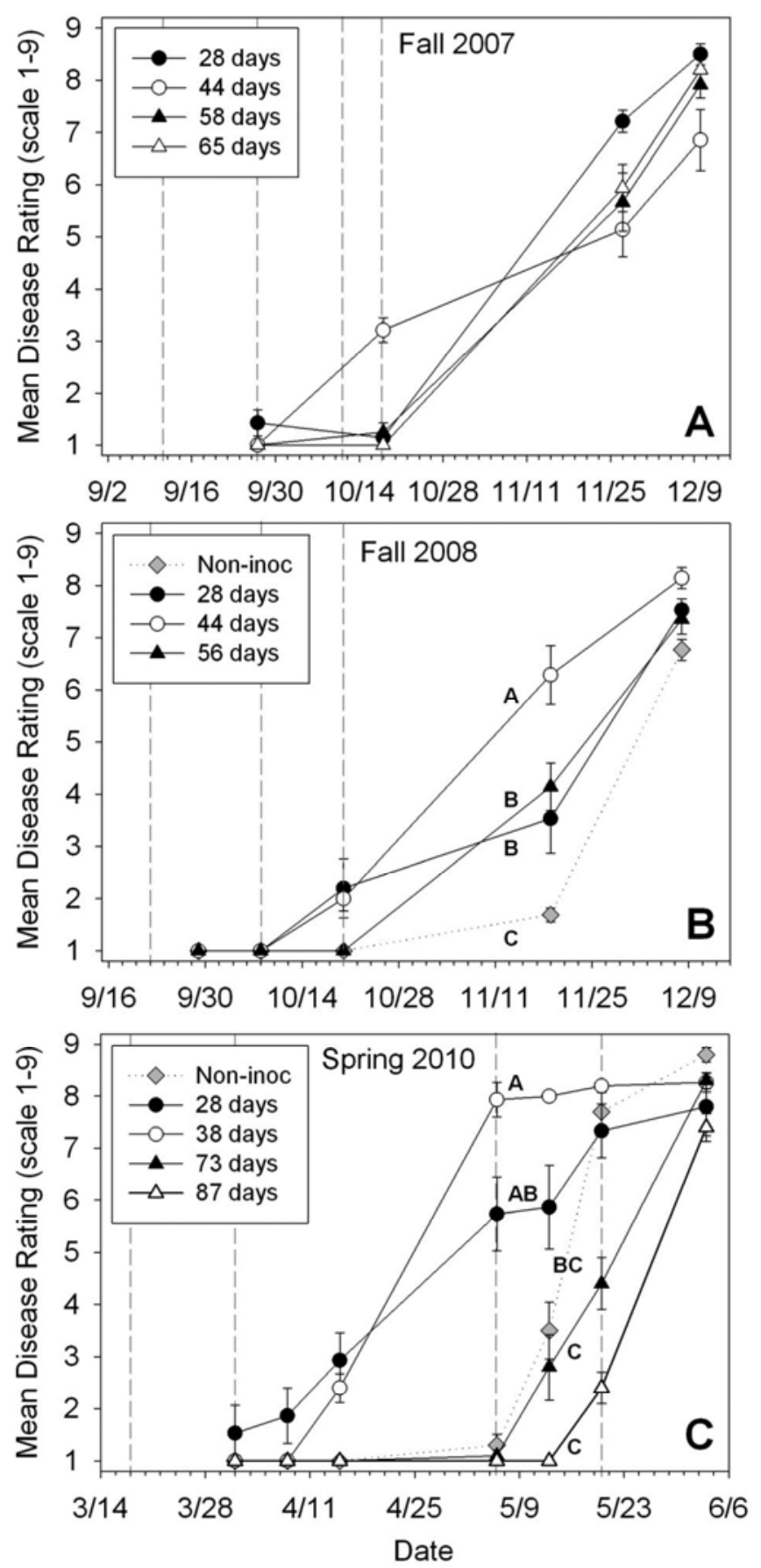

Fig. 9. Disease progress curves for Squash vein yellowing virus in 'Crimson Sweet' watermelon plants in plant age field trials in A, fall 2007, B, fall 2008, and C, spring 2010. Disease ratings are based on a 1 to 9 scale described previously (14). Inoculation dates are indicated by vertical dashed lines in each graph, such that the first inoculation corresponds with the youngest plant age group (e.g., 28 days old in 2007), the second inoculation date corresponds with the next plant age group (e.g., 44 days old in 2007), etc. Noninoculated controls were present in 2008 and 2010. Symbols represent the individual rating dates and span the period for which the AUDPC was calculated. Letters represent the results of mean separation tests among AUDPCs (in B and C) with areas sharing the same letter being statistically equivalent according to Fisher's LSD. 
tion site to the "sink," which is either the fruit, or the growing point (i.e., vine tip) in plants without fruit, and also in about one-third of plants with fruit when inoculated at or before 55 days old. This is consistent with results found in our prior study of SqVYV distribution in field-collected watermelon plants (29). Plants inoculated with SqVYV had a clear reduction in both plant and fruit weights, alteration in rind and flesh colors, and lower sucrose concentration and higher acid content. These physiological changes were greatest in plants inoculated at younger ages.

SqVYV was more widely distributed in planta in the current greenhouse trials compared to our earlier field studies (29), likely due to the differing growth habits of the plants. Each greenhouse plant was trimmed to a single stem with only one or no fruit. In contrast, each plant in the previous field studies had multiple stems and multiple fruits of varying maturity. It would be interesting to remove fruits from field-grown plants infected with SqVYV and determine if plants still decline. Also, the field-grown plants in the previous study were likely inoculated by whiteflies multiple times during their growth and over a greater proportion of the plant, as compared to the mechanical inoculations of the lower leaves of the plants in the current study. It would also be interesting to inoculate plants above the point of fruit attachment and determine whether SqVYV moves toward the fruit or toward the growing tip.

The co-inoculation treatments of SqVYV and PRSV-W were included because SqVYV was commonly found in mixed infections with PRSV-W at the time the study was initiated (2). Since then, the whitefly-transmitted viruses CuLCrV and CYSDV have subsequently been detected in Florida cucurbit crops and weeds $(1,3,5,7,26,35)$, and these viruses often occur in mixed infections with SqVYV and/or PRSV-W $(5,29)$. Under field conditions, it appears that infection with SqVYV leads to vine decline of watermelon plants regardless of the presence of other viruses. However, it would be interesting to determine the effect of mixed infections with CuLCrV and CYSDV on SqVYV symptoms and distribution to more fully understand the ecology of these viruses and develop more integrated and comprehensive management strategies.

Inoculation of watermelon plants with SqVYV or SqVYV+ PRSV-W, especially at younger plant ages, had significant physiological effects on plant and fruit quality. The major components of watermelon fruit quality are rind and flesh color, and sugar and malic acid content $(8,27,30)$. Rind color influences consumer purchase preferences (23). Rind color of fruits from SqVYVinoculated plants was noticeably off-color, with larger fruits generally having a pale appearance compared to fruits from mockinoculated plants, resulting in a less marketable fruit. Smaller fruits tended to become chlorotic/necrotic at the blossom end. Sucrose is the major determinant of sweetness (8) and was significantly lower in fruits from virus-inoculated plants compared to mock-inoculated plants, particularly in plants inoculated at 55 days old. These results are consistent with the previously observed reduction in sugar content in fruits from watermelon plants infected with Zucchini yellow mosaic virus, which was also greatest in plants infected at younger ages (19). Acidity also affects the taste of watermelon and is linked to fruit metabolism (8). The amount of organic acids increased in fruits from virus-infected plants, particularly in plants inoculated at 55 days of age, mirroring the decrease in sucrose at this age. Under commercial conditions, watermelon vine decline does not appear on a large scale until plants are at or very near harvest. When this occurs, there are often numerous healthy looking mature fruits. Unfortunately, the changes in fruit quality induced by SqVYV can be detected even if the mature fruits are harvested before plants fully decline. Because changes to fruit quality can be detected with the onset of disease symptoms, it appears that growers have no options of recovering losses attributed to watermelon vine decline once it is detected in the field (11).

Localization of SqVYV nucleic acid in the vascular system and in particular the phloem (Figs. 2 and 7) is consistent with previous reports of SqVYV nucleic acid and protein in the phloem $(2,33)$, and we can infer that its presence likely interferes with nutrient uptake and distribution. Nutrient analysis of mock-inoculated watermelon plants in the plant age greenhouse trial indicated nutrient levels sufficient for normal plant growth. However, levels of several key macro- and micronutrients in SqVYV- or SqVYV+ PRSV-W-inoculated plants significantly increased, while others decreased, indicating that the nutrient situation is complex. For instance, major reductions in $\mathrm{K}$ and $\mathrm{N}$ were detected in plants of different ages when inoculated with SqVYV or SqVYV+PRSV-W, which is typical of plants in poor health where the vascular system has been compromised. The Ca increase in SqVYV- and SqVYV+ PRSV-W-inoculated plants is especially interesting, as Ca deficiency in watermelon fruits causes blossom end rot (15), a physiological disorder that disrupts cell wall formation and cell membrane integrity (25). We observed external rind necrosis (Fig. 3A) and placental separation (Fig. 4A) at the blossom end of fruits from plants inoculated with SqVYV or SqVYV+PRSV-W at 42 days old, and rumpling of the rind and splitting of fruits from plants inoculated with SqVYV or SqVYV+PRSV-W at 69 or 83 days old. These fruit symptoms have characteristics of blossom end rot, but we note that $\mathrm{Ca}$ levels were higher rather than lower in virusinoculated plants. However, we also note that water relations significantly impact $\mathrm{Ca}$ flux in plants, and we have demonstrated that inoculation with SqVYV affects water relations (i.e., reduction of fresh weight in virus-inoculated plants; Figs. 3A and 8). Perhaps $\mathrm{Ca}$ levels were higher in plants because it was not being translocated to fruits. Unfortunately, we only measured $\mathrm{Ca}$ in green/ vegetative parts of plants and not the fruits, and thus cannot directly address this issue with our current data.

Little is known about the effects of virus infection on nutrient flux patterns or nutrient partitioning, although some work has shown that nutrients play an indirect role in pathogenicity for bacteria and fungi (18). Previous work with Tropical soda apple mosaic virus (a tobamovirus) infection of Tropical soda apple (Solanum viarum) demonstrated increased levels of $\mathrm{P}, \mathrm{Mg}, \mathrm{B}$, and $\mathrm{Cu}$, and reduced levels of Mo in infected leaves (22). In the present work, virus infection had no measurable effect on levels of $\mathrm{P}, \mathrm{Cu}$, or Mo. However, higher levels of $\mathrm{Mg}$ and $\mathrm{B}$ in plants of different

Table 3. Results of mixed model analyses of the age of plant at inoculation with Squash vein yellowing virus on the development of watermelon vine decline in the plant age field trials

\begin{tabular}{|c|c|c|c|c|c|c|c|c|c|}
\hline & \multicolumn{3}{|c|}{ Fall 2007} & \multicolumn{3}{|c|}{ Fall 2008} & \multicolumn{3}{|c|}{ Spring 2010} \\
\hline & Num df & Test statistic ${ }^{\mathbf{a}}$ & $P$ & Num df & Test statistic ${ }^{\mathbf{a}}$ & $P$ & Num df & Test statistic ${ }^{\mathbf{a}}$ & $P$ \\
\hline Fixed effect & & $F$ & $P>F$ & & $F$ & $P>F$ & & $F$ & $P>F$ \\
\hline Inoculation timing & 3 & 1.33 & 0.351 & 3 & 9.25 & 0.006 & 4 & 9.48 & 0.011 \\
\hline Random effect & & $\chi^{2}$ & $P>\chi^{2}$ & & $\chi^{2}$ & $P>\chi^{2}$ & & $\chi^{2}$ & $P>\chi^{2}$ \\
\hline Block & 1 & 0.10 & 0.752 & 1 & 0.00 & 1.00 & 1 & 0.52 & 0.471 \\
\hline Residual & & $86.49^{\mathrm{b}}$ & & & $85.53^{b}$ & & & $79.01^{\mathrm{b}}$ & \\
\hline
\end{tabular}

${ }^{\text {a }} F$ tests were performed on fixed effects with numerator degrees of freedom (Num df) as shown in table and denominator degrees of freedom of 6 , 8 , and 5.62 for the fall 2007, fall 2008, and spring 2010 experiments, respectively. The denominator degrees of freedom were calculated using the 'kenwardroger' option in SAS (i.e., /ddfm=kr). Likelihood ratio $\chi^{2}$ tests were performed on random effects with degrees of freedom values shown in table. Column shows the difference between the $-2 \cdot \log$ likelihoods of the full and reduced models.

$\mathrm{b}$ The $-2 \cdot \log$ likelihood of the full model. 
ages inoculated with SqVYV or SqVYV+PRSV-W compared to mock-inoculated plants is quite similar to the previous Tropical soda apple mosaic virus work. Whether these results from two taxonomically different plant-virus systems indicate a common effect of virus infection on $\mathrm{Mg}$ and $\mathrm{B}$ levels requires further testing.

Disease progress curves in the two fall field trials were very similar, suggesting that plant age at time of inoculation with SqVYV had little effect on epidemic development (Fig. 9). For the spring field trial, AUDPCs were markedly different within the trial, and the shapes of the progress curves were different than those in the fall trials. However, all curves for plots with SqVYV-inoculated plants shared three important features: (i) the first instance of disease within a plot was detected at the first rating after inoculation, with the exception of plants inoculated at 28 days old in the 2008 fall trial; (ii) mean final disease severity was greater than 7.4 in all epidemics, except for plants inoculated at 44 days old in the 2007 trial; and (iii) disease severity began to rapidly increase at $\sim 14$ dpi. Although whitefly management was practiced in the field trials, it was not perfect, as evidenced by the appearance of disease in the noninoculated controls. Based on the timing of disease onset in the noninoculated controls, it appears that whiteflies had the greatest impact in 2010 where symptoms began to develop prior to completion of treatment inoculations.

In commercial watermelon production, symptoms of SqVYV-induced vine decline are usually first noticed at or just before harvest. However, in our experimental inoculations, SqVYV-infected plants showed symptoms on leaves, petioles, vines, and fruit, if present, and began to decline in 12 to 16 days regardless of plant age at time of inoculation, or greenhouse or field location. Younger plants died outright before fruit were even set (2). Older plants in the current study required 2 to 4 additional days to decline but died unless they had no fruit, in which case no vine decline was observed. This suggests that in commercial production conditions, plants are not being inoculated until the latter part of the season, despite the abundance of whiteflies that often exists early in the season in many fields. One may hypothesize that there is a lack of viruliferous whiteflies early in the production season, or perhaps the virus titer within the plant must reach a threshold level to trigger vine decline. It is surprising that large-scale SqVYV outbreaks have not been reported to date from transplant production or early season fields. Watermelon is the only crop observed to decline naturally in the field, but several other cucurbit species (in genera other than watermelon) have recently been found to decline under experimental conditions in greenhouse and field trials (36). Similar vascular localization of SqVYV RNA has been observed in all SqVYV-infected cucurbit species regardless of the symptom phenotype, suggesting that this localization is not the only determinant of the induction of vine decline symptoms (36).

Taken together, these results suggest that SqVYV infection is occurring late in the season under Florida conditions, probably about 12 to 16 days before symptoms of vine decline become obvious. Likely, this is exacerbated by the presence of multiple vines and multiple fruits on typical field plants, and the standard commercial practice of reducing irrigation water just prior to harvest to increase sugar content for sweeter fruit. The combination of a watermelon plant with a compromised vascular system, reduced input of water, and very large fruits serving as a "sink" for both water and photosynthates is probably ideal for the sudden collapse of plants known as watermelon vine decline. Whether these host physiological responses are shared with other ipomoviruses remains to be seen.

\section{Acknowledgments}

We thank Carrie Vanderspool, Jeff Smith, Reid Lewis, Joanne Hodge, Wayne Brown, Chris Lasser, Jennifer Ikerd, Rod Systma, David Ballesteros, Shannon Clark, and Heather Capobianco for their excellent technical assistance, and Nihat Guner, Randy Johnson, and Benny Bruton for their helpful advice on growing greenhouse watermelon crops. Financial support was provided in part by USDA CSREES SCRI grant 2008-04890 and the National Watermelon Association.

\section{Literature Cited}

1. Adkins, S., Polston, J. E., and Turechek, W. W. 2009. Cucurbit leaf crumple virus identified in common bean in Florida. Plant Dis. 93:320.

2. Adkins, S., Webb, S. E., Achor, D., Roberts, P. D., and Baker, C. A. 2007. Identification and characterization of a novel whitefly-transmitted member of the family Potyviridae isolated from cucurbits in Florida. Phytopathology 97:145-154.

3. Adkins, S., Webb, S. E., Baker, C. A., and Kousik, C. S. 2008. Squash vein yellowing virus detection using nested polymerase chain reaction demonstrates that the cucurbit weed Momordica charantia is a reservoir host. Plant Dis. 92:1119-1123.

4. Adkins, S., Webb, S. E., Roberts, P. D., Kousik, C. S., Stansly, P. A., Bruton, B. D., Achor, D., Muchovej, R. M., and Baker, C. A. 2010. A review of Ipomoviruses and watermelon vine decline in Florida. Pages 333-337 in: Bemisia: Bionomics and Management of a Global Pest. P. A. Stansly and S. E. Naranjo, eds. Springer, New York.

5. Adkins, S., Webster, C. G., Baker, C. A., Weaver, R., Rosskopf, E. N., and Turechek, W. W. 2009. Detection of three whitefly-transmitted viruses infecting the cucurbit weed Cucumis melo var. dudaim in Florida. Plant Health Progress doi:10/1094/PHP-2009-1118-01-BR

6. Adkins, S., Webster, C. G., Kousik, C. S., Webb, S. E., Roberts, P. D. Stansly, P. A., and Turechek, W. W. 2011. Ecology and management of whitefly-transmitted viruses of vegetable crops in Florida. Virus Res. 159:110-114.

7. Akad, F., Webb, S., Nyoike, W., Liburd, O. E., Turechek, W., Adkins, S., and Polston, J. E. 2008. Detection of Cucurbit leaf crumple virus in Florida cucurbits. Plant Dis. 92:648.

8. Chisholm, D. N., and Picha, D. H. 1986. Distribution of sugars and organic acids within ripe watermelon fruit. HortScience 21:501-503.

9. Christie, R. G., and Edwardson, J. R. 1994. Light and electron microscopy of plant virus inclusions. Monogr. 9, revised. University of Florida, Institute of Food and Agricultural Sciences.

10. Egel, D. S., and Adkins, S. 2007. Squash vein yellowing virus identified in watermelon (Citrullus lanatus) in Indiana. Plant Dis. 91:1056.

11. Huber, M. 2006. Taking vital vines. Citrus Veg. Mag. 70:22-24

12. Hull, R. 2002. Matthews' Plant Virology, 4th ed. Academic Press, London.

13. Kenward, M. G., and Roger, J. H. 1997. Small sample inference for fixed effects from restricted maximum likelihood. Biometrics 53:983-997.

14. Kousik, C. S., Adkins, S., Turechek, W. W., and Roberts, P. D. 2009. Sources of resistance in U.S. plant introductions to watermelon vine decline caused by Squash vein yellowing virus. HortScience 44:256-262.

15. Latin, R. X. 1996. Nutritional disorders. Pages 60-61 in: Compendium of Cucurbit Diseases. T. A. Zitter, D. L. Hopkins, and C. E. Thomas, eds. American Phytopathological Society, St. Paul, MN.

16. Li, W., Hilf, M. E., Webb, S. E., Baker, C. A., and Adkins, S. 2008. Presence of P1b and absence of HC-Pro in Squash vein yellowing virus suggests a general feature of the genus Ipomovirus in the family Potyviridae. Virus Res. 135:213-219.

17. Louro, D., Quinot, A., Neto, E., Fernandes, J. E., Marian, D., Vecchiati, M. Caciagli, P., and Vaira, A. M. 2004. Occurrence of Cucumber vein yellowing virus in cucurbitaceous species in southern Portugal. Plant Pathol. 53:241.

18. Marschner, H. 1998. Mineral Nutrition of Higher Plants, 2nd ed. Academic Press, New York.

19. Mora-Aguilera, G. 1995. Aphid vector dynamics and temporal and spatial characterization of watermelon virus epidemics. Ph.D. diss. University of Florida, Gainesville.

20. Moreno, P., Ambrós, S., Albiach-Martí, M. R., Guerri, J., and Peña, L. 2008. Citrus tristeza virus: A pathogen that changed the course of the citrus industry. Mol. Plant Pathol. 9:251-268.

21. Olson, S. M., Simonne, E. H., Stall, W. M., Roberts, P. D., Webb, S. E., and Smith, S. A. 2010. Cucurbit production in Florida. Pages 83-105 in: Vegetable Production Handbook for Florida, 2010-2011. S. M. Olson and B. Santos, eds. University of Florida IFAS Extension, Gainesville.

22. Overholt, W. A., Markle, L., Rosskopf, E., Manrique, V., Albano, J., Cave, E., and Adkins, S. 2009. The interactions of tropical soda apple mosaic tobamovirus and Gratiana boliviana (Coleoptera: Chrysomelidae), an introduced biological control agent of tropical soda apple (Solanum viarum). Biol. Control 48:294-300.

23. Pardo, J. E., Gomez, R., Tardaguila, J., Amo, M., and Varon, R. 1997. Quality evaluation of watermelon varieties (Citrus vulgaris S.). J. Food Qual. 20:547-557.

24. Pićo, B., Villar, C., and Nuez, F. 2003. Screening Cucumis sativus landraces for resistance to cucumber vein yellowing virus. Plant Breed. 122:426-430.

25. Pilbeam, D. J., and Morley, P. S. 2007. Calcium. Pages 121-144 in: Handbook of Plant Nutrition. A. V. Barker and D. J. Pilbeam, eds. Taylor and Francis, Boca Raton, FL.

26. Polston, J. E., Hladky, L. L., Akad, F., and Wintermantel, W. M. 2008. First report of Cucurbit yellow stunting disorder virus in cucurbits in Florida. Plant Dis. 92:1251

27. Pratt, H. K. 1971. Melons. Pages 207-232 in: The Biochemistry of Fruits and Their Products, Vol. 2. A. C. Hulme, ed. Academic Press, New York.

28. Storey, H. H. 1936. Virus diseases of East African plants. VI. A progress report on studies of the diseases of cassava. East Afr. Agric. J. 2:34-39. 
29. Turechek, W. W., Kousik, C. S., and Adkins, S. 2010. Distribution of four viruses in single and mixed infections within infected watermelon plants in Florida. Phytopathology 100:1194-1203.

30. U.S. Dep. Agric. 2006. United States Standards for Grades of Watermelons. USDA, AMS Fruit and Vegetable Programs Fresh Products Branch.

31. U.S. EPA Method 3052. 1997. Microwave assisted acid digestion of siliceous and organically based matrices, Test methods for evaluating solid waste, physical/chemical methods. EPA Publ. SW-846, 3rd ed., as amended by Updates I, II, IIB, III, and IIIB finalized in the Federal Register on June 13, 1997.

32. U.S. EPA Method 6010B. 1997. Inductively coupled plasma-atomic emission spectrometry, Test methods for evaluating solid waste, physical/chemical methods, EPA Publ. SW-846, 3rd ed., as amended by Updates I, II, IIB, III, and IIIB finalized in the Federal Register on June 13, 1997.

33. Webb, S. E., Adkins, S., and Reitz, S. R. 2012. Semipersistent whitefly transmission of Squash vein yellowing virus, causal agent of viral watermelon vine decline. Plant Dis. 96:839-844.

34. Webster, C. G., and Adkins, S. 2012. Low genetic diversity of Squash vein yellowing virus in wild and cultivated cucurbits in the U.S. suggests a recent introduction. Virus Res. 163:520-527.

35. Webster, C. G., Kousik, C. S., Roberts, P. D., Rosskopf, E. N., Turechek, W. W., and Adkins, S. 2011. Cucurbit yellow stunting disorder virus detected in pigweed in Florida. Plant Dis. 95:360.

36. Webster, C. G., Kousik, C. S., Turechek, W. W., Webb, S. E., Roberts, P. D., and Adkins, S. 2013. Squash vein yellowing virus infection of vining cucurbits and the vine decline response. Plant Dis. 97:1149-1157.

37. Winter, S., Koerbler, M., Stein, B., Pietruszka, A., Paape, M., and Butgereitt, A. 2010. Analysis of cassava brown streak viruses reveals the presence of distinct virus species causing cassava brown streak disease in East Africa. J. Gen. Virol. 91:1365-1372. 